\title{
The Trends of Endodontic and Prosthodontic Treatment by Postgraduate Students in University of Malaya
}

\author{
Aimi Amalina Ahmad ${ }^{1}$, Poornima Sawri Rajan ${ }^{1}$, Prema Sukumaran ${ }^{1}$, Mariam Abdullah ${ }^{1}$, \\ Nora Sakina Mohd Noor ${ }^{1}$, Asfand Ali Khan ${ }^{1}$
}

\section{KEYWORDS}

Trend, fixed prosthodontics, primary endodontics, secondary endodontics

\section{ABSTRACT}

This study is aimed to provide an insight into the types of treatment carried out by postgraduate students in the past 10 years. A retrospective study was carried out between November 2019 and February 2020 by deriving data from postgraduate students' clinical logbooks of three different cohorts of Master of Clinical Dentistry (Restorative Dentistry in Conservative Dentistry) in 2010, 2013 and 2016. This retrospective data was systematically extracted from the records and tabulated categorically using an Excel spreadsheet (Microsoft Office Excel 2019). A descriptive analysis was carried out to further evaluate the results. Overall, the types of treatment carried out in the field of endodontics and fixed prosthodontics has changed in the past 10 years. An increasing trend is seen in the placement of all ceramic crowns and primary root canal treatment procedures, while a decreasing pattern is evident for secondary root canal procedures and placement of dental bridges.

\section{INTRODUCTION}

Restorative dentistry is a field of dentistry that deals with the study, diagnosis and integrated management of diseases of the teeth and their supporting structures and the rehabilitation of the dentition to functional and aesthetic requirements of the individual. At the Faculty of Dentistry, University of Malaya, postgraduate students enrolled in the clinical postgraduate program (Master of Clinical Dentistry, (Restorative Dentistry in Conservative Dentistry) are actively involved in managing patients who require treatment in the disciplines of fixed prosthodontics and endodontics.

In relation to Fixed Prosthodontics, cases are mainly focused on permanent (fixed) dental prostheses, also referred to as indirect restorations. These

\footnotetext{
${ }^{1}$ Department of Restorative Dentistry, Faculty of Dentistry, University of Malaya, Kuala Lumpur, Malaysia

*Correspondence: prema@um.edu.my
}

include crowns, dental bridges, inlays, onlays and veneers. The materials used for the fabrication of these restorations are either metal, ceramic or a combination of both. The design of each fabricated prosthesis depends on the clinical and functional requirement and they could either be a full metal, metal ceramic or all ceramic prosthesis.

Endodontics is the branch of dentistry concerned with the morphology, physiology and pathology of the human dental pulp, and peri radicular tissues. Its study and practice encompass basic and clinical sciences which include the biology of the normal pulp and the aetiology, diagnosis, prevention and treatment of diseases and injuries of the pulp and associated peri radicular conditions [1]. The most common endodontic treatment is root canal treatment (RCT). In endodontics however, the expertise of the specialists goes beyond just a conventional root canal treatment. In this specialised field, postgraduate students are also taught how to treat cases of vital pulp therapy, separated instruments, re-treatment, endodontic- 
periodontal lesions, and cases which may require endodontic surgery.

In the Master of Clinical Dentistry (Restorative Dentistry in Conservative Dentistry) program at the University of Malaya, graduate students carry out a vast amount of root canal procedures that vary from easy, moderate to difficult depending on many different factors such as primary or secondary treatment, position of tooth, root and tooth morphology, curvature of root, and others [2]. With the evolution and improvement in technology, students can now use the microscope along with ultrasonic tips to handle more complex cases.

Dentists learn the fundamentals of fixed prosthodontics in dental school and many forms of continuous education. However, there is more to fixed prostheses than the fundamentals, such as the technical aspects, laboratory skills, and keeping up with the current developments of dental materials. For full coverage prosthesis, previously till the late 1990's, porcelain fused to metal (PFM) restorations have been the preference, all ceramic crowns were occasionally issued, and metal free crowns were rarely used [3]. Even though PFM crowns exhibited better longevity and survival, all ceramic crowns have been used occasionally over the last four decades as an alternative for PFM crowns to overcome their aesthetic limitations. However, this has changed as the popularity of all ceramic crowns has immensely increased with the availability of newer types of ceramics with better properties [4]. For dental bridges, PFM is still the most common choice as it provides the best strength that is much needed when replacing multiple teeth [5].

Despite the program being delivered for the past 20 years, there is no data documenting the types and quantity of various endodontic and prosthodontic treatments undertaken by the postgraduate students. It is therefore the purpose of this study to quantify the types of treatment carried out by postgraduate students in the past 10 years. The specific objectives are to evaluate the types of root canal treatment performed and to quantify the dental crowns and bridges placed by postgraduate students in the past 10 years. The rationale of this study is to have baseline data on the treatment provided by postgraduate students which can serve as future reference to further improve the conduct and delivery of curriculum as well as delivery of treatment rendered by students.

\section{MATERIALS AND METHODS}

The data for this study was derived from postgraduate students' clinical logbooks of three Ann Dent UM. 2021, 28:34-39 different cohorts of Master of Clinical Dentistry (Restorative Dentistry in Conservative Dentistry) in 2010, 2013 and 2016. The number of students in each cohort is shown in Table 1.

Table 1 Number of students in each cohort

\begin{tabular}{cc}
\hline Cohort & No. of students \\
\hline 2010 & 5 \\
\hline 2013 & 5 \\
\hline 2016 & 6 \\
\hline
\end{tabular}

Retrospective data on the clinical cases completed in Year 2 and Year 3 of the program were systematically extracted from the logbook and tabulated. The data extracted were as follows:

1. Total number of primary root canal treatments completed

2. Total number of secondary root canal treatments completed

3. Total number of crowns issued

4. Total number of bridges issued

Primary and Secondary root canal treatment completed were further subdivided based on type of tooth; anterior, premolar and molar. Dental crowns and bridges were further categorised based on material; all ceramic, metal-ceramic and full metal. The data were tabulated in a systematic manner in Excel spreadsheet (Microsoft Office Excel 2019). A descriptive analysis was carried out to further evaluate the results.

\section{RESULTS}

The total number of endodontic and prosthodontic treatments completed by postgraduate students in University of Malaya over the past 10 years are summarized in Table 2.

Overall, there was an increasing trend in the total number of primary root canal treatments. The total number of primary root canal treatments done by postgraduate students in cohort 2016 were 1.5 folds more than in cohort 2010. Besides that, a decreasing trend in the total number of secondary root canal treatments was observed whereby the total number of secondary root canal treatments performed by postgraduate students in cohort 2016 were less than 2.6 folds compared to cohort 2010.

The total number of root canal treatments performed on anterior teeth, premolars and molars are shown in Table 3 . With regards to primary root canal treatments, the total number of primary root canal treatments on molars show an increasing trend compared to premolars and anterior teeth 
with a total of 218 root canal treatments on molars, 109 on premolars and 113 on anterior teeth. In contrast, there is a decreasing trend in the total number of secondary root canal treatments performed, with a total of 15 involving molars, 29 premolars and 34 anterior teeth.

Table 2 Total number of endodontic and prosthodontic treatments completed by postgraduate students in cohort 2010, 2013 and 2016

\begin{tabular}{|c|c|c|c|}
\hline & 2010 & 2013 & 2016 \\
\hline \multicolumn{4}{|l|}{ Endodontics } \\
\hline $\begin{array}{l}\text { Primary } \\
\text { endodontics }\end{array}$ & 118 & 146 & 176 \\
\hline $\begin{array}{l}\text { Secondary } \\
\text { endodontics }\end{array}$ & 46 & 20 & 12 \\
\hline Total & 164 & 166 & 188 \\
\hline \multicolumn{4}{|l|}{$\begin{array}{l}\text { Fixed } \\
\text { Prosthodontics } \\
\text { (Crowns) }\end{array}$} \\
\hline All Ceramic Crowns & 19 & 18 & 56 \\
\hline $\begin{array}{l}\text { Metal-Ceramic } \\
\text { Crowns }\end{array}$ & 70 & 153 & 52 \\
\hline Full Metal Crowns & 11 & 3 & 1 \\
\hline Total & 100 & 174 & 109 \\
\hline \multicolumn{4}{|l|}{$\begin{array}{l}\text { Fixed } \\
\text { Prosthodontics } \\
\text { (Bridges) }\end{array}$} \\
\hline All Ceramic Bridges & 3 & 2 & 6 \\
\hline $\begin{array}{l}\text { Metal-Ceramic } \\
\text { Bridges }\end{array}$ & 39 & 21 & 29 \\
\hline Full Metal Bridges & 0 & 0 & 0 \\
\hline Total & 42 & 23 & 35 \\
\hline
\end{tabular}

Table 2 also shows a 3-fold increase in the number of all ceramic crowns and bridges placed by postgraduate students in the 2016 cohort compared to the preceding cohorts. In addition, the general trend also shows more crowns (383) placed compared to bridges (100) over the past 10 years.

Table 3 Total number of primary and secondary root canal treatments performed by postgraduate students in cohort 2010, 2013 and 2016

\begin{tabular}{lccc}
\hline $\begin{array}{l}\text { Primary } \\
\text { Endodontics }\end{array}$ & $\mathbf{2 0 1 0}$ & $\mathbf{2 0 1 3}$ & $\mathbf{2 0 1 6}$ \\
\hline Anterior & 30 & 46 & 37 \\
\hline Premolars & 34 & 33 & 42 \\
\hline Molars & 54 & 67 & 97 \\
\hline $\begin{array}{l}\text { Secondary } \\
\text { Endodontics }\end{array}$ & & & \\
\hline Anterior & 22 & 8 & 4 \\
\hline Premolars & 16 & 6 & 7 \\
\hline Molars & 8 & 6 & 1 \\
\hline
\end{tabular}

\section{DISCUSSION}

The increase in primary root canal treatment cases and the decrease in secondary cases is similar to the trend in the annual report by the Malaysian Ministry of Health (MOH) [6]. This could be due to patients making more informed decisions and preference to salvage their tooth rather than getting it extracted. The National Oral Health Survey Report conducted in 2018 showed an increase in the number of patients who sought treatment at the Restorative Specialists' clinics [7].

One other possible reason for this trend could be the use of newer technology such as rotary instruments which have made it easier for general clinicians to carry out endodontic procedures more efficiently [8]. In addition, the increasing number of restorative specialist and primary services offered by $\mathrm{MOH}$, may also influence the increasing trend of patients seeking treatment at the Restorative Specialists' clinics. According to Azarpazhooh et al. 2013, most patients with apical periodontitis preferred to retain their teeth with root canal treatments followed by crowns rather than extracting and replacing them with bridges [9]. Overall inclination of these patients are towards root canal treatment and retention rather than extraction of a painful tooth with $97.2 \%$ for anterior teeth and $89.6 \%$ for posterior teeth [9].

Meanwhile, for secondary root canal cases, a declining pattern is seen. A few reasons may contribute to this change; one of which is the increasing popularity of dental implants. In recent years, implant-supported prostheses are an option that many patients consider to replace missing teeth [10]. This could be due to the fact that there is an increasing awareness and interest among the Malaysian public on dental implants [11]. A recent study has shown that a single tooth implant has a similar success rate to non-surgical root canal treatment with a 95\% survival rate with a mean 7.5year follow-up [12]. In addition, the advances in research have proven secondary root canal treatment to have a low success rate. $\mathrm{Ng}$ et al. in 2008 concluded in a systematic review that the pooled estimated success rate of secondary root canal treatment was $77 \%$ [13]. This could contribute to the declining pattern for secondary root canal treatments.

The presence of a pre-operative periapical lesion, the apical extent of the root filling and the quality of coronal restoration proved significant prognostic factors when determining the success rate [13]. Recently in 2021, a prospective cohort study was conducted to analyze the prognostic factors as well 
as the outcome of secondary root canal treatment cases over a 4-year period by using the cone beam computer tomography as a tool to measure volumetric change of periapical radiolucency [14]. This study was able to conclude that the outcome of secondary root canal treatment was predictable with a reduction of periapical lesions in $94.6 \%$ cases.

An increasing trend in the total number of allceramic crowns placed by postgraduate students was observed in this study. The development of tooth-colored, high-strength ceramic materials in conjunction with advancements in digital and adhesive dentistry has led to an increasing trend in the prescription of all-ceramic prostheses. A similar trend worldwide was also reported in which $32 \%$ to $56 \%$ of 376 UK dental practitioners preferred the use of tooth-colored and metal-free crowns for both anterior and posterior teeth since 2008 [15]. The reason for this is the high demand for metal free restorations by patients. The ceramic that most dentists prescribed were zirconia-based ceramics and lithium disilicate [15].

In addition, increasing demand for speedy and more aesthetic treatments from patients has led to a significant change to the treatments offered by dental professionals. Moreover, patients' demands for metal-free restorations may be largely accountable to the decreasing trend of metal-based crowns. Furthermore, improvements in dental biomaterials science have led to the fabrication of high-strength ceramics that can tolerate occlusal forces and yield optimum aesthetic results [15].

Based on a systematic review done in 2018, full ceramic crowns used for anterior teeth showed survival rates of $97.6 \%$ at 5 years, very much comparable to those seen for metal-ceramic crowns at $98.3 \%$ [16]. For posterior teeth, the survival rate of reinforced glass-ceramic crowns (93.7\%) was almost similar to those obtained for metal-ceramic crowns (95.6\%) [17]. This review is one of the many studies that further reinforce the increased usage of full ceramic crowns in the present day.

A decreasing trend in the placement of bridges was also observed in this study. From the prosthodontic view, implant-supported prostheses are preferred because of its excellent survival potential without the need to prepare the adjacent teeth $[18,19,20]$. Besides that, there has been an increasing preference of either dentists or patients for replacement of affected teeth with implantsupported prosthesis [21, 22].
Based on a systematic review by Pjetursson et al. 2007, a 5-year survival rate of conventional bridges (93.8\%) was comparable to the implant-supported bridges (95.2\%) [23]. In addition, the 10-year survival of conventional bridges was almost similar to the implant-supported bridges at $89.2 \%$ and $86.7 \%$, respectively [23]. This review has led to a decreasing placement of conventional fixed bridges and further encouraged the placement of implantsupported fixed dental prostheses.

Perhaps a similar study can be conducted in ten years to evaluate the change in treatment trend at the postgraduate clinic. We may see an exponential increase in implant treatment with a corresponding reduction in primary or secondary root canal treatment in line with the global trend. Or we may even see a complete reversal of the trend with an increase demand of root canal treatment possibly with the discovery or introduction of a new material or technology which can profoundly increase the success or such treatment.

A future study to look at the increasing application of digital dentistry in postgraduate teaching and learning in endodontics and prosthodontics can also provide us with an insight on how these technologies can supplement and maybe even be at the forefront of dentistry in the not-so-distant future.

The authors also foresee, with the introduction of digital workflow, a change in trend of treatment delivery including types of prostheses prescribed, speed and efficiency of treatment delivery. We hope this will enhance postgraduate students' learning and patients' treatment experience in University of Malaya. Besides, with the introduction of mono specialty training, the types of cases and range of complexity of these cases may increase as students have more time to focus on the specialty driven management of cases.

\section{CONCLUSION}

The types of treatment carried out in the field of endodontics and fixed prosthodontics has changed in the past 10 years. An increasing trend is seen in the placement of all ceramic crowns and primary root canal treatment procedures, while a decreasing pattern is evident for secondary root canal procedures and placement of dental bridges. 


\section{ACKNOWLEDGEMENT}

The authors would like to thank support staff at the Department of Restorative Dentistry for assistance provided in data collection.

\section{DECLARATION OF INTEREST}

The authors report no conflict of interest. The authors alone are responsible for the content of this article.

\section{REFERENCES}

1. American Dental Association, American Dental Association. Health Policy Resources Center. Future of dentistry: today's vision, tomorrow's reality. American Dental Association; 2001.

2. American Association of Endodontics. What's the difference between a dentist an endodontist? https://www.aae.org/patients/why-see-an-endodontist/whats-difference-dentist-endodontist. 2020.

3. Brunton PA, Christensen GJ, Cheung SW, Burke FJ, Wilson NH. Contemporary dental practice in the UK: indirect restorations and fixed prosthodontics. Br Dent J 2005; 198(2): 99-103.

4. Canadian Agency for Drugs and Technologies in Health. Porcelain-Fused-to-Metal Crowns Versus AllCeramic Crowns. Canadian Agency for Drugs and Technologies in Health; 2016.

5. Affairs AC. Direct and indirect restorative materials. J Am Dent Assoc 2003; 134(4): 463-72.

6. Ministry of Health Malaysia. Oral health programme in Malaysia - A review. 2009.

7. Ministry of Health Malaysia. Oral Health Programme Ministry of Health Malaysia. Annual report. Retrieved http://ohd.moh.gov.my/images/pdf/annual_rpt/annual_rpt18.pdf. 2018.

8. Sonntag D, Delschen S, Stachniss V. Root-canal shaping with manual and rotary Ni-Ti files performed by students. Int Endod J 2003; 36(11):715-23.

9. Azarpazhooh A, Dao T, Figueiredo R, Krahn M, Friedman S. A survey of patients' preferences for the treatment of teeth with apical periodontitis. J Endod 2013; 39(12):1534-41.

10. Narby B, Bagewitz IC, Söderfeldt B. Factors explaining desire for dental implant therapy: analysis of the results from a longitudinal study. Int J Prosthodont 2011; 24(5):437-44.

11. Kohli S, Bhatia S, Kaur A, Rathakrishnan T. Public knowledge and acceptance of dental implant treatment in Malaysian Population. J Interdiscip Dent 2014; 4(2): 76-80.

12. Vahdati SA, Torabinejad M, Handysides R, Lozada J. A Retrospective Comparison of Outcome in Patients Who Received Both Nonsurgical Root Canal Treatment and Single-tooth Implants. J Endod 2019; 45(2):99103.

13. Ng YL, Mann V, Gulabivala K. Outcome of secondary root canal treatment: a systematic review of the literature. Int Endod J 2008; 41(12):1026-46.

14. Zhang MM, Fang GF, Chen XT, Liang YH. Four-year Outcome of Nonsurgical Root Canal Retreatment Using Cone-beam Computed Tomography: A Prospective Cohort Study. J Endod 2021; 47(3):382-90.

15. Jum'ah AA, Creanor S, Wilson NH, Burke FJ, Brunton PA. Dental practice in the UK in 2015/2016. Part 3: aspects of indirect restorations and fixed prosthodontics. Br Dent J 2019; 226(3):192-6.

16. Pjetursson BE, Valente NA, Strasding M, Zwahlen M, Liu S, Sailer I. A systematic review of the survival and complication rates of zirconia-ceramic and metal-ceramic single crowns. Clin Oral Implants Res 2018; 29:199-214.

17. Pjetursson BE, Sailer I, Zwahlen $\mathrm{M}$, Hämmerle $\mathrm{CH}$. A systematic review of the survival and complication rates of all-ceramic and metal-ceramic reconstructions after an observation period of at least 3 years. Part I: single crowns. Clin Oral Implants Res 2007; 18:73-85.

18. Salinas TJ, Eckert SE. In patients requiring single-tooth replacement, what are the outcomes of implant-as compared to tooth-supported restorations? Int J Oral Maxillofac Implants 2007; 22 Suppl:71-95.

19. Naert I, Koutsikakis G, Duyck J, Quirynen M, Jacobs R, Van Steenberghe D. Biologic outcome of implantsupported restorations in the treatment of partial edentulism: Part 1: A longitudinal clinical evaluation. Clin Oral Implants Res 2002; 13(4):381-9.

20. Ruskin JD, Morton D, Karayazgan B, Amir J. Failed root canals: the case for extraction and immediate implant placement. J Oral Maxillofac Surg 2005; 63(6):829-31. 
21. Thomas MV, Beagle JR. Evidence-based decision-making: implants versus natural teeth. Dent Clinics 2006; 50(3):451-61.

22. Di Fiore PM, Tam L, Thai HT, Hittelman E, Norman RG. Retention of teeth versus extraction and implant placement: treatment preferences of dental faculty and dental students. J Dent Educ 2008; 72(3):352-8.

23. Pjetursson BE, Brägger U, Lang NP, Zwahlen M. Comparison of survival and complication rates of toothsupported fixed dental prostheses (FDPs) and implant-supported FDPs and single crowns (SCs). Clin Oral Implants Res 2007; 18:97-113.

\section{Editorial History}

Date of Submission: 13 Jan 2021

Review \& Revision: 11 Feb 2021 - 25 Apr 2021

Accepted: 11 May 2021

Published: 21 June 2021

License Information: This work is licensed under a Creative Commons Attribution 